\title{
An International Language for the World to Come
}

\author{
Young-Hee Chung \\ sejong university
}

\section{Introduction}

In the past, particularly before the invention of the Korean Alphabet Hangul ${ }^{1}$, the Korean people had struggled with Chinese characters because the knowledge of Chinese characters was essential to access to information.

Now, Koreans are in a similar situation. The only difference is the target language has been switched from Chinese to English: the Korean people are struggling with English.

Why do we learn foreign languages? Whitmore (1950) gives four main motives. One is for ordinary intercourse, business or social, usually by speech; a second is for engaging in diplomacy or directives, which may involve both speaking and writing; a third is for gaining scientific or technical information, largely from written sources; and a fourth is for what may broadly be called cultural purposes, which again will deal mostly with written language.

In recent years, when nations have been getting closer and closer through advanced technology and consequently international exchanges have become more frequent and significant, the obstacle that foreign languages pose is more keenly felt and the linguistic variety of the present world is becoming an increasing burden on international communication.

Translations and interpretations could help to reduce such

\footnotetext{
* Assistant Profeffor, English Department, Sejong University

This paper was supported by 1995 grants from Dea-Yang Foundation

${ }^{1}$ The Korean alphabet. Hangul was invented in 1446 by King Sejong.
} 
linguistic barriers. Indeed, international organizations like the United Nations and the European Union $^{2}$ make an extensive use of interpretations, which, though cumbersome, appears to be working. However, the cost and inconvenience involved is immense: in the European Union, according to Large (1985), a third of all the staff and over half the Parliament's staff are employed due to the multilingual situation, and almost 50 percent of the administrative expenditure are related to language costs (Large 1985:199). In addition to that, interpretations and translations have their limitation in what they can achieve. Therefore, they cannot be the ultimate solution to linguistic barriers.

In these circumstances, it seems to be natural to have a vision of a common language for international communication. The interest in an international language is not a new one. It can be traced back to the first century BC when Diodorus Siculus, a Greek historian was interested in the idea of a Universal language. St Hildegrade, a 12th century Abbess of Rupertsberg in the diocese of Mainz is known acutally to have constructed a language composed of 900 words using 23 letters of alphabet. (Large 1985).

Despite the long history in the schemes for international language, the hope for a single linguistic medium for international communication has not been fulfilled: even Esperanto, the most promising scheme of them all, has ended up as the interest of a small fraction of the world ${ }^{3}$. This, however, does not necessarily mean that the hope cannot be fulfilled in the world to come.

This paper aims to explore the hope for an international language, by considering and assessing possible approaches to the problem. The first part of this paper will examine the possibility of using a single natural language as an international language and its problems. Next, the alternative of constructing an artificial language will be discussed. Previous artificial language schemes will be examined and a new direction will be suggested.

\footnotetext{
${ }^{2}$ The European Community has been renamed as the European Union since 1995.

${ }^{3}$ Today, it is estimated that there are 30,000,000 membership in 188 nations over the world.
} 


\section{Natural Language as an International Language}

\section{(a) A Historical Review}

In the case of Western civilization, there were periods when a natural language was used as an international language across linguistic boundaries. Latin played an international role for centuries before 18th century in Western Europe. Latin was the medium of instruction in schools; it carried a role as the language of learned discourse. Yet by early 18th century French replaced Latin, assuming the role of international language in Western Europe.

In those periods, when international communication was not only regional but also confined to a few elites or ruling classes, it was not likely to cause much problem for a natural language like Latin or French to assume the role of international language. In recent years, however, when international relations are continually extending and multiplying, so that international communication is required on a world-wide scale comprising a wide variety of people, the adoption of one natural language as an international language might cause serious problems.

\section{(b) English as an International Language?}

In the world today, English is the most widespread language for international communication, so is potentially the best candidate for an international language.

Supporters of English as an international language base their argument on the following two advantages English is believed to have: the most widespread language in the current international use, and its relative linguistic simplicity. But, I will argue below that these two advantages are not only spurious but also lack evidence.

(c) The Spread of English

While 152 nations of the world listed by Banks (1975) are reported to share among themselves at least 75 official languages, 
English, French, Spanish and Arabic alone account for about 95 countries. In all, as of January 1, 1975, English was the sole "designated" official language of some 21 countries, and the designated co-official language of some 16 more. $^{4}$ (Andrew W. Conrad and Joshua A. Fichman 1976). As regards the English speaking population, it is estimated that the number of native speakers of English remains constant about 315 million. The number of users of English as a second or foreign language is increasing dramatically; these are estimated at 300 and 100 million people respectively (Crystal 1985). This number, however, does not form such a large portion as is believed to do given that the whole world population is around 3.5 billion.

The increasing spread of English in recent years is analyzed by the first director of the Center for Applied Linguistics as follows:

The spread of English is as significant in its way as is the modem use of computers. When the amount of information needing to be processed came to exceed human capabilities, the computer appeared on the scene, transforming the process of planning and calculation. When the need for global communication came to exceed the limits set by language barriers, the spread of English accelerated, transforming existing patterns of international communication. (Ferguson 1983)

By establishing parallels between the computer and English, the director implies that the world-wide spread of English is a natural and the only answer to the need for a common language of the world

4 The following statistics on English speakers around the world is from Andrew Conrad and Joshua Fishman (1977). English mother tongue countries : Britain, USA, Ireland, Canada(around 60\%). Australia, Newzealand, Barbados, Jamaica, Trinidad, Guyana(45\%), Granada, Bahamas

Countries having English designated as an official language : Botswana. Cameroon, Fiji, Gambia, Ghana, India, Lesotho, Liberia, Malawi, Malta, Mauritius, Namibia, Nauru, Nigeria, Philippines, Rhodesia, Sierra Leone, Singapore, South Africa, Swaziland, Tanzania, Tonga, Uganda. Western Samor, Zambia 
today and thus contributes greatly as the computer does.

Such parallels between the computer and English miss two points: one is that the forces which propelled English forward are not the same in nature as those which propelled the spread of the computer. The other is that the implication of the world-wide spread of English is not of the same nature as those of the computer. First, the outstanding factor in extending the use of English has undoubtedly been the political power and influence of the English-speaking nations and the superiority they attained in various fields of commerce, technology, and military affairs. Political power was especially effective during the colonial era, strongly contributing to the position of English as a non-native language. This is well evidenced by the fact that most of the nations where English is designated as an official language or has an official status were colonies or in colony-like status under Britain or America (A. Conrad and J. Fishman 1975). ${ }^{5}$ Furthermore, as noted by Phillipson, the spread of English was also greatly abetted by the expenditure of large amounts of government and private foundation funds in the period $1950-1970^{6}$, perhaps the most ever spent in history in support of the propagation of a language (Phillipson 1992). Judging from these facts, the spread of English should not be seen entirely as a natural outcome of the world-wide need for a common language; rather, it is the result of imperialism and propagation.

More recently, oppositions to the advance of English come from many parts: from colonized people, European parliamentarians, and so on. Many previous colonies are trying to get rid of the traces and influences of Western imperialism left behind and to seek their indentity, political and cultural. Cultural identity cannot be complete without linguistic identity. Therefore, for instance, in Kenya there

\footnotetext{
${ }^{5}$ Countries in which there is some official status for English: Miyanma, Ethiopia, Israel, Kenya, Malaysia, Pakistan, Sri Lanka, Sudan. All the countries listed above where Englis $\mathrm{h}$ is an official language or has some official status were colonies of Britain or America e xcept for Ethiopia.

${ }^{6}$ For details on the expenditure on the English propagation, refer to Phillipson (1991).
} 
are indications of an increased emphasis on Swahili ${ }^{7}$ and less on English (Njoroge 1986). More and more there are such trends, more and more oppositions there will be to the spread of English worldwide.

Secondly, since natural languages have their own native speakers unlike the computer, the dominance of one language seems likely to lead to a dominating-dominated relationship among languages and consequently among speakers of the languages. Furthermore, unlike the computer, which is culture-neutral, language is a product of culture and values. Therefore the dominance of one language over others is likely to lead to the spread of the culture embedded in the dominating language. In this view, the dominance of English, as argued by Phillipson (1992), will possibly lead to the spread of the culture and values embedded in the language, particularly in the circumstances where those values are reinforced in many social domains. The spread of Western culture and values in several countries in Asia and Africa cannot be said to have nothing to do with the spread of English, even though language is admittedly not the only impetus to the pervasiveness of the culture.

\section{(d) Linguistic Superiority of English}

Linguistic superiority is frequently associated with dominant languages. For instance, when it was the international language of the European ruling class, French was contended to be superior to other languages: it is elegant, clear and has the "natural order of its syntax": those languages which did not have the same syntax as French were not "logical" and were therefore inferior.

Similarly, a linguistic case is presented in favor of English as an international language: its relative simplicity compared with many other languages. George Steiner (1975) among others argues that over the centuries many grammatical complexities of English have been discarded and its vocabulary combines the roots of Latin,

\footnotetext{
${ }^{7}$ Swahili is a Bantu language, which is used as a Lingua Franca in the large area of Afri ca.
} 
German and French. So, consequently English is easier to acquire than any other second language whether in Asia, Africa or Latin America.

Ease of acquisition is an important characteristic of candidates for international language, of course. However, it is doubtful that English has such a characteristic of simplicity and consequently ease of acquisition as is claimed. To cite some linguistic complexities of English, pronunciation and spelling are irregular ${ }^{8}$, accent placement is not transparent, word inflection is still substantial ${ }^{9}$ tense, aspect, and modals are complicated in its usage and so on. To them can be added its extensive vocabulary and lots of idioms. (A piece of empirical evidence showing that English is not easy to learn on the part of non-European language speakers can be provided from a Korean case: 6 years of intensive learning of English from Middle to High school does not guarantee for most Koreans any proficiency in reading, let alone speaking and writing.)

Moreover, contrary to the claim above, the borrowing of the roots of Latin, German and French has made English more difficult to acquire, at least on the part of non-European language speakers, since such combination has resulted in substantial synonyms, and therefore extension of vocabulary and more complications in grammar (i.e. aid (French origin) and help (Anglo-Saxon) origin; the prefixes in -(Latin origin as in incapable) and un -(Germanic origin as in unkind)).

In addition to all these, it needs to be pointed out that ease of acquisition of second language largely depends on the native language of learners, not on the relative simplicity of grammar. So English might be easier to acquire for a German than for a Korean as Korean might be easier for a Japanese than for an American. The linguistic argument in favor of English as an international language, thus, does not hold strong.

\footnotetext{
${ }^{8}$ For example, the sound (s) is represented in several different ways in spelling as in sea, lace, and loss.

${ }^{9}$ For example, irregular verbs in English such as bring-brought, or go-went.
} 


\section{(e) Linguicism}

The strongest opposition to the adoption of English as an international language concerns the inequality it could bring about We live in a world characterized by inequality of gender (sexism), nationality (nationism). race (racism), class(classism), and language (linguicism). Linguicism, a concept which was introduced by Phillipson as describing a sub-type of linguistic imperialism, refers to ideologies and structures where language is the means for effecting or maintaining an unequal allocation of power and resources (Phillipson 1992). Linguicism is easy to occur in circumstances where one language takes the dominant position over others. This point is clearly articulated by a Soviet author, who argues that the country whose language is used (as a linguistic media for international communication) would be in a privileged position because its scientists need not spend time in studying a foreign language but can devote more time to science. That country consequently would gain great opportunities for economic and ideological expansion because scientific works would be followed by technical specifications, advertisements and mass communication media which would give it an advantage in political relations, (cited from Large 1985:195)

In a similar context can the dominance of English worldwide be understood: the dominance of English ensures the continued allocation of more material resources to English than to other languages and benefit those who are proficient in English (Phillipson 1992). Considering the proficiency in foreign languages is extremely hard to attain in normal circumstances, non-English speaking countries could not but continue to suffer unfair treatment and disadvantages in the international relations.

\section{Prospects for Artificial Language}

An alternative solution for international communication is to 
construct an artificial language. An artificial language can avoid the problems involved in natural languages; since it does not have its own native speakers, the problem of inequality between languages will disappear; also, a carefully-constructed artificial language can get rid of grammatical irregularities and complexities. These advantages of artificial language have motivated so many people to invest a vast amount of time and effort to its construction.

Numerous schemes of artificial language ${ }^{10}$ have appeared but no artificial language has assumed the role of international language so far. According to Large (1985). the main reason for the failure is not that artificial languages have any linguistic shortcomings but that they lack powerful vehicles of dissemination. His argument is based on the observation that languages have been spread by political and military power (i.e. Latin throughout the Roman Empire, Spanish and Portuguese in Central and South America, Russian in Eastern Europe), by economic activity (i.e. English throughout the world in the present and previous centuries), by religion (i.e. Arabic in the Middle East and North Africa), by arts and sciences (i.e. Latin, Greek, English and many more) and more recently, by tourism (Le. English) (Large 1985:198).

It is doubtful, however, whether the same process of dissemination will apply in the world to come, where economic activities will not just be confined to a few powerful countries, where no military or/and political power will be allowed to impose something on other nations, where tourism will not be the possession of a few rich countries. The future international society will no longer allow one dominant power, each nation will have a voice of equal, or similar weight. Therefore, in the world to come, the need for an international language which belongs to no nation will be higher than ever and so is the chance of success of an artificial language. It has to be emphasized that the construction of artificial language is not for the world today but for the world to

\footnotetext{
10 According to Large(1995), close to one thousand artificial languages have been constru cted to date.
} 
come. We need to prepare for the future by constructing an artificial language which can meet the needs of future generations. In this respect, the case of the Korean alphabet Hangul provides a good example; the Korean alphabet Hangul has begun to be widely used among Korean people about 500 years after it was first invented in $1446 .{ }^{11}$

\section{A New Perspective for Artificial Language}

\section{(a) Previous Schemes}

There are two conceivable approaches to the construction of artificial language: creation of new language, and modification of some existing language. But it is not easy to draw the line between these two approaches since even creation of new language is frequently based on grammar and vocabulary drawn from one or more natural languages. Esperanto, one of the artificially created languages, for example, resembles the languages of European, particularly Latin.

Among created artificial languages are Esperanto, Glossa, Interlingua and Eurolengo. ${ }^{12}$ Examining these artificial languages reveals that they resemble in large part European languages. Therefore, grammatical categories such as tense, aspect, plurality and case are adopted without a significant change as are used in European languages. Its vocabulary is also largely based on European languages, and word formation uses a lot of affixes as is in European languages.

An example of modified language is Basic English ${ }^{13}$, which is a simplified version of English. Basic English tries chiefly to solve the problem of rich and extensive vocabulary of natural language (around 20,000 words). However, the apparent reduction of

\footnotetext{
${ }^{11}$ The Korean alphabet Hangul was adopted as the writing norm in 1948 .

${ }^{12}$ For more details on these artificial languages, refer to arge(1985)

${ }^{13}$ For more details, refer to Large(1985).
} 
vocabulary to 850 English words, according to its critics, resulted in the complication in morphology, syntax and idiomatic use (Large 1985).

As can be noticed, it is European, more specifically Western European languages which played a central role in artificial language schemes, created or modified; languages other than European languages have almost been ignored. Such a bias against other languages is defended by Alexander Gode, who is a supporter of Interlingua ${ }^{14}$, an artificial language. He claims that if proportional representation were to be given to the major oriental tongues, for example, the end product would be a language that no one found easy to understand; it would no longer be likely intelligible to Westerners, yet the great discrepancies between individual oriental languages would mean that the Chinese or Japanese would be little or no better placed to understand it than Interlingua (Large, 1985). How much of his claim is valid? His point of view is largely on the side of Westerners. Why does he think that a language with influence of Oriental languages is unintelligible to Westerners? The same logic applied, the reverse should hold true, too: that is, a language with influence of Western languages should be unintelligible to Oriental people.

As regards the discrepancies among oriental languages, the comparison between Chinese and Japanese is not valid, since they belong to distinct language families. What counts is not Western languages or Oriental languages but language families. 7 distinct language families ${ }^{15}$ are reported to be established in the world and European languages merely represent only one of the 7 language families.

I am not arguing that a universal language should be constructed in such a way that each and every language in the world is equally

\footnotetext{
${ }^{14}$ For more details on interlingua, refer to Large(1985).

${ }^{15}$ Seven language families are the Indo-European family, the Finno-Ugric family, the Altaic family, the Afro-Aasiatic family, the Nigro-Congo family, the Malayo-Polynesian family, and the Sino-Tibetan family. Chinese belongs to the Sino-Tibetan family, while Japanese is not firmly associated with a particular language family. There might be more language families other than these.
} 
represented. Rather, I would like to propose that a scheme of construction of international language, whether it is creation or modification, needs to be approached differently from the previous ones, that is, to escape from the main stream of Western languages and seek its solution in more universal perspectives.

\section{(b) A New Perspective for Artificial Language: Pidgin}

The term 'pidgin' has been defined in several different ways, two of which will be given here.

A pidgin is a language which has arisen as the result of contact between peoples of different languages, usually from mixing of the languages. (Unesco 1963:46)

A pidgin is a variety whose grammar and vocabulary are very much reduced. The resultant language must be native to no one. (Bloomfield 1933:474)

Pidgins were ignored and despised as being mere jargons or bastardized versions of standard languages, but today's pidgins may be attestation of what happens when languages come into contact.

The fact that pidgins develop in a situation where speakers in contact do have no common language to communicate with seems to suggest something for the construction of a common language for international communication.

Based on the definitions above, we can characterize pidgin by the two features-mixture and reduction. Mixture in pidgins is most conspicuous at the level of the lexicon (i.e. vocabulary); mixing at the syntactic and morphological levels is not significant. Reduction means that a pidgin makes use of a smaller set of structural relations and items in the syntax, phonology and lexicon than the related languages. Reduction, however, should not be confused with impoverishment as pointed out by Muhlhausler. Reduction would imply greater grammatical regularity, which is attested to allow more referential and non-referential power of pidgin languages 
(Muhlhausler 1986).

One of the things about pidgins which draw our particular attention is that there are pervading similarities apparent in the world's pidgins, no matter how grographically distant they might be, and no matter how unrelated the languages involved might be. ${ }^{16}$ Among the shared characteristics are absence or little of inflections (analytic over synthetic), SVO word order, the loss of grammatical tense, the absence of the copula (adjectives function as verbs), the absence of number distinction in nouns and no gender distinction, invariable word order in question, and so on. With respect to the lexicon, the number of lexical items is around 1500, compared to 25-30,000 items in an ordinary language. Similar constraints on phonology are also proposed to exist among pidgins: the reduction of phonological inventories (consonants: p,t,k,b,d,g,f,s,m,n, 1/r,w,y vowels: i,u,e,o,a) absence of consonant clusters, and so on (Romaine 1988).

Various explanations have been advanced for the shared characteristics across pidgins. Among them is a universality view, which attributes such similarities to the existence of a universal simplification process. That is, the world's pidgins are similar since the capacity for linguistic simplification and accommodation is innate and universal.

The universality view gets support from the studies on child language acquisition. These studies provide evidence that language acquisition is biologically triggered and linguistic behaviour of children reflects an innate urge to impose a pattern on language. Such a finding may be related to Chomsky's LAD (Language Acquisition Device). ${ }^{17}$ If it is true that all humans are born with a

\footnotetext{
${ }^{16}$ It is estimated that around 100 pidgin and creole languages are spoken in all parts of the world. For more details on the similarities among pidgins, refer to Todd(1974) or Suzanne(1988).

17 The hypothesis of biological innateness of the language faculty has been most vigorous ly advanced by Noam Chomsky. According to him, the development of language in child ren is guided by a set of "innate ideas and principles," (which is Language Acquisition D evice) that is, a genetically determined linguistic capacity that all humans are endowed wi th at birth.
} 
biological predisposition to acquire and manipulate language, it might be possible that they get access or refer to this universal device for linguistic simplification. As supporting evidence for it, similarities are reported to exist between child language acquisition and pidginization (Suzanne 1988).

If similiarities among pidgins are innate and universal as claimed by some, then an international language constructed based on such universal features (whether created or modified) will not only be universal in a true sense but also be relatively easy to acquire regardless of the learner's native tongue.

Further support for the universality view comes from an experiment on the second language acquisition. According to this experiment, linguistic similarities exist between 2nd language acquisition and pidginization : reliance on word order (SVO) rather than inflections for expressing grammatical relations, lack of inversion in questions, verb forms unmarked for tense and aspect, no + Verb pattern in negation, and so on (Schumann 1981). This fact seems to suggest that a universal simplification process exists and applies both in second language acquisition and pidginization. Considering an international language would be at most a second language for most of its users, universal features or its simplification processes both in pidgins and second language acquisition seem to point in the right direction for the construction of international language.

Lastly, similarities are also reported to exist between pidgins and sign language (Deuchar : 1986), which can be yet further evidence for the universal features of pidgins.

\section{Conclusion}

In this paper, I have tried to deliver the following three points: the need of a common language for international communication, the undesirability of the adoption of a single natural language as an international language, and a suggestion that studies on pidgins may 
provide a new perspective for the construction of an artificial language for the world to come. The first two points may be agreed among many people, whereas the third point, that is, the construction of an artificial language may be suspected of its reality by many. In this connection, I need to emphasize that the construction of an artificial language is for the world to come, and the fact that all previous schemes of artificial language have failed does not necessarily preclude future success. Remember that history does not repeal, but progress. An artificial language based on true universality may not repeat the same failure as its predecessors.

\section{Reference}

Banks, Arthur s., ed. 1975. Political Handbook of the World: (1975). New York;McGraw Hill.

Crystal, David. (1985). How many millions? The statistics of English today 1.1.

Deuchar, M. (1986). -Sign Languages as Creoles and Chomsky's

Notion of Universal Grammar', in Modgil S and Modgil, C (ed.)

Noam Chomsky Consensus and Controversy. Brighton, Falmer

Press.

Ferguson. C. A. (1983). Foreword, in Kachru (ed.) 1983b.

Fishman. Joshua; Robert Cooper, and Andrew Conrad. (1977). The Spread of English. Newbury House Publishers, Inc.

Hancock. Ian F.(ed.) (1985). Diversity and Development in Englishrelated Creoles. Karoma Publishing INC., Ann Arbor.

Kachru, Braj B. (1976). "Models of English for the Third World:White Man's Linguistic Burden or Language Pragmatics?. TESOL Quarterly Vol. 10 No.2, 221-239. ed. (1983b). The other tongue : English Across Cultures. Oxford: Pegamon.

Large, Andrew. (1983). The Foreign-Language Barrier:Problems in Scientific Communication. London:Deutsch.

(1985). The Artificial Language Movement. Basil Blackwell. 
(1995). The Prospects for an International Language', to appear in Universal Language 1. Sejong University Press.

Maher, John. (1985). "The Development of English as an International Language of Medicine". Applied Linguistics, Vol. 7 No.2,206-218.

Muhleriiausler, Peter. 1986. Pidgin and Creole Linguistics. Basil Blackwell.

Njoroge. kimani wa'. (1986). "Multilingualism and Some of its Complications for Language Policy and Practices in Kenya in Centre of African Studies 1986:327-54

Phillipson, Robert. (1992). Linguistic Imperialism. Oxford University Press.

Priva, Edmond. (1923), 국제어 에스페란토의 역사. 이현숙. 이중기. 허성 옳김. 도서출판 자유문고, Seoul.

Romaine, Suzanne. (1988). Pidgin and Creole Languages. Longman. Smith. Larry. (1981). English for Cross-Cultural Communication. St. Martin's Press; New York.

Steiner, George. (1975). After Babel: aspects of language and translation. Oxford:Oxford University Press.

Todd, Loreto. (1974). Pidgin and Creole. Routledge and Kegan Paul. Tonkin, Humphrey. (1979). "Equalizing Langauge", Journal of Communication 29,124-133.

Whitmore. Charles E. (1950). "The Problem of a Universal Language", The Scientific Monthly 337-342.

\section{Afterword}

'Universal Language' is published annually by the Institute for World Language. The Institute for World Language was founded in 1995 with the objective of undertaking research into the creation of a universal language for international communication.

The first issue of Universal Language consists of articles presented at a symposium on The Necessity of an International 
Language and Hangul's Implication for It', held on October 24, 1995 in Seoul. The symposium had two main aims: first, to stimulate recognition or recall of the necessity for a single international linguistic medium, and second to evaluate ways to achieve the goal of its development.

Four of the articles- 'the Need for a Universal Language and Methods of its Creation as Suggested by Hangul' by Myungkun Choo; The Prospects for an International Language* by A. Large; 'Natural and Artificial International Language' by B. Connie: and 'An International Language for the World to Come* by Younghee Chung- all agree on the necessity of a single linguistic medium for international communication. But they disagree as to ways such a linguistic medium should be selected. A. Large and B. Comrie seem to be in favor of adopting a natural language as an international language, while Young-Hee Chung disagrees vehemently. The article 'International and Historical Significance of Hangul' by J. Diamond is, on the other hand, not on the problem of international language in a strict sense though the ideas it contains concerning the invention of writing systems could shed light on the associated problems.

We have just taken a first step in the long journey to the goal of a universal language for international communication. The success of the remaining journey, I believe, depends heavily on the enthusiastic involvement of as many people as possible in the research. I hope many will be encouraged to take part in this ambitious research project through 'Universal Language'.

Lastly, I would like to express my deepest thanks to those who have made the publication of this journal possible. 